\title{
Effect of RBI Grade 81 on strength characteristics of clayey subgrade
}

\author{
Shiva Prashanth Kumar Kodicherla ${ }^{1^{*}}$ (1) and Darga Kumar Nandyala ${ }^{2}$
}

\author{
${ }^{*}$ Correspondence: \\ prashanthetc1024@gmail. \\ com; Shivaprashanth.K@xjtlu. \\ edu.cn \\ ${ }^{1}$ Department of Civil \\ Engineering, Xi'an Jiaotong- \\ Liverpool University (XJTLU), \\ Suzhou, Jiangsu province, \\ China \\ Full list of author information \\ is available at the end of the \\ article
}

\begin{abstract}
The present study deals with the effect of Road Building International Grade 81 (RBI Grade 81) on strength characteristics of the clayey subgrade. A wide range of tests was conducted on various percentages of RBI Grade 81 subgrade mixtures such as Atterberg limits, compaction characteristics, California Bearing Ratio (CBR) and Unconfined Compression Strength tests (UCS). It can be noticed that the CBR of clayey subgrade has increased significantly with the addition of RBI Grade 81. Similarly, the maximum dry density (MDD) has decreased and the optimum moisture content (OMC) has increased with RBI Grade 81 addition to subgrade. The strength of clay subgrade at $8 \%$ of RBI Grade 81 has improved 3-3.5 times as compared to the natural clayey subgrade. Overall, it can be concluded that RBI Grade 81 is suggested as a potential stabilizing agent especially for clayey subgrades.
\end{abstract}

Keywords: Clayey subgrade, Unconfined compressive strength, California bearing ratio, $\mathrm{RBI}$ Grade 81

\section{Introduction}

Clayey subgrade soils are known as troublesome soils in causing damages especially to the buildings and highway pavements. The damages caused to the structures particularly the lightweight buildings and pavements due to expansive clay soils are comparable to the damages caused due to the natural hazards of earthquakes and floods. Worldwide the expansive clay soils are considered to be problematic and pose several challenges for engineers when involved in construction activities. To avoid such problems, these soils are required to treat or stabilize before the commencement of the construction project. Soil stabilization is one of the viable and technically feasible options to improve the physical and engineering behaviour of the expansive subgrade. Also, soil stabilization enhances the shear strength and improves the bearing capacity of soil as well as the project requirements [1]. It also enables the soil to fit the requirements under specific weather and traffic conditions especially the highway pavements. In most of the cases, in-situ soil would not be able to bear traffic/wheel loads coming on it and many roads fail due to poor soil subgrade.

In the recent past, one of the trending stabilizers which have been considered by the engineers is Road Building International Grade 81 (RBI Grade 81). It is a natural inorganic soil-stabilizer that can modify the properties of soil to strengthen the subgrade of highway pavements. RBI Grade 81 is a worldwide patented additive which includes 
India. It is a combination of naturally occurring compounds that provides a good solution to create low-cost roads and foundation layers of motorways. It encourages faster application periods as the road can be opened to traffic within $24 \mathrm{~h}$ of final compaction and it provides a dust free surface. If the nature of the soil changes for different depths, most of the methods for stabilization cannot be used but it has a wide range of response spectrum being an eco-friendly material that has many advantages over the other stabilizers used. It can reduce $30-40 \%$ of the construction cost, drastically increases the strength of the pavements, and reduce transport and earth moving costs by $60 \%$.

Apart from the previous investigations it is evidently proven that unconfined compressive strength (UCS); soaked California Bearing Ratio (CBR) increases in addition of RBI Grade 81. It is also noticed from the literature that it is suitable to improve the performance of the soft soils acting as a good stabilizer. Similarly, UCS and CBR are also reduced with increasing the dosage of sodium silicate which pose the limitation to be used as a stabilizer. There was a considerable decrease in the liquid limit and swell index with the increased dosage of the stabilizer. Furthermore, it is also evidenced that there was an increase in the CBR and UCS of soils with the increase in the dosage of the stabilizer [2, 3]. Soil admixed with RBI Grade 81 has shown a reduction in Plasticity Index (PI) of soil. Increase in UCS corresponds to the increase in RBI Grade 81 content and it was found to be significant at $6 \%$ of RBI Grade 81 and further addition makes a fair increase in UCS. There was a drastic change in soaked CBR with RBI Grade 81 and it was found to be significant at addition of $6 \%$ stabilizer for unsoaked and 4 days of soaking as it achieves the required value as per the Indian Road Congress (IRC) standards [4, 5]. Fatigue life test results indicate a high fatigue life for all treated soils when subjected to repeated loading (considering 1/3 of UCS) as compared to the untreated soils [6]. A wide range of variation was observed in addition of RBI Grade 81 for lateritic (red soil) and black cotton soil [7]. The UCS of specimens treated with RBI Grade 81 increased approximately by $250 \%$ for a curing period of 28 days as compared to virgin soil and the CBR value improved approximately by $400 \%$. An increasing trend in soil strength behaviour with increasing percentage of RBI Grade 81 suggested its potential applications in soil stabilization [8]. Heavy compaction influence has been noticed on fly ash treated granular sub-base and also $\mathrm{CaCl}_{2}$ treated swelling soils $[9,10]$. The different percentages of RBI Grade 81 varying from 2 to $8 \%$ were added and test results indicated $42 \%$ reduction in plasticity index for kaolinite, $4 \%$ for red soil and $116 \%$ for lateritic soils. Similarly, OMC increased and MDD decreased with the addition of RBI Grade 81 for red and kaolinites [11]. The stabilized UCS sample increases with increase in the period of curing but the increased percentage in strength was more upon lime addition compared to RBI Grade 81 [12]. From these aforementioned review of the literature, an attempt is made in this investigation to understand the effect of RBI Grade 81 on strength characteristics of the clayey subgrade. Further details of the study are furnished in the following sections.

\section{Experimental program}

\section{Materials used}

\section{Soil}

The soil used in this study was collected from open pits near Patancheru area, Hyderabad, India. After the collection, soil was processed and stored in an airtight containers in the laboratory. The basic tests were conducted according to the Indian 
Standard Code of Practice of testing of soils. The basic properties of soil and the gradation curve are presented in Table 1 and Fig. 1, respectively. From this figure, it can be noticed that the soil has $3 \%$ of gravel and $44 \%$ of sand. The fines content (passing $0.075 \mathrm{~mm}$ sieve) present in the soil is $53 \%$.

\section{RBI Grade 81}

RBI Grade 81 accredited by Central Road Research Institute (CRRI), New Delhi was collected from the local construction industry. Response spectrum is the range of soils for which a particular stabilizer can be used. The range over which a soil stabilizer can be used is not the only criteria for its acceptability; the durability, cost, and ease of application also requires an intellectual consideration. The wide range of RBI Grade 81 spectrum is shown in Fig. 2. The physical and chemical properties of RBI Grade 81 are presented in Tables 1 and 2 respectively.

\section{Tests conducted}

Different laboratory tests were conducted on the soil samples as per Indian Standard Code of Practice for Testing of Soils. The liquid limit (LL) and plastic limit (PL) tests

Table 1 Basic index properties of soil

\begin{tabular}{lll}
\hline S. no. & Property & Value \\
\hline 1 & Liquid limit (LL), \% & 48 \\
2 & Plastic limit (PL), \% & 21 \\
3 & Plastic index (PI) & 27 \\
4 & California Bearing Ratio (CBR) & 3 \\
5 & Unconfined compressive stress (kPa) & 100 \\
6 & Maximum dry density, MDD $\left(\mathrm{kN} / \mathrm{m}^{3}\right)$ & 17.5 \\
7 & Optimum moisture content, OMC (\%) & 17.5 \\
8 & Cohesion, C (kPa) & 50 \\
9 & UCS failure strain (\%) & 10 \\
\hline
\end{tabular}

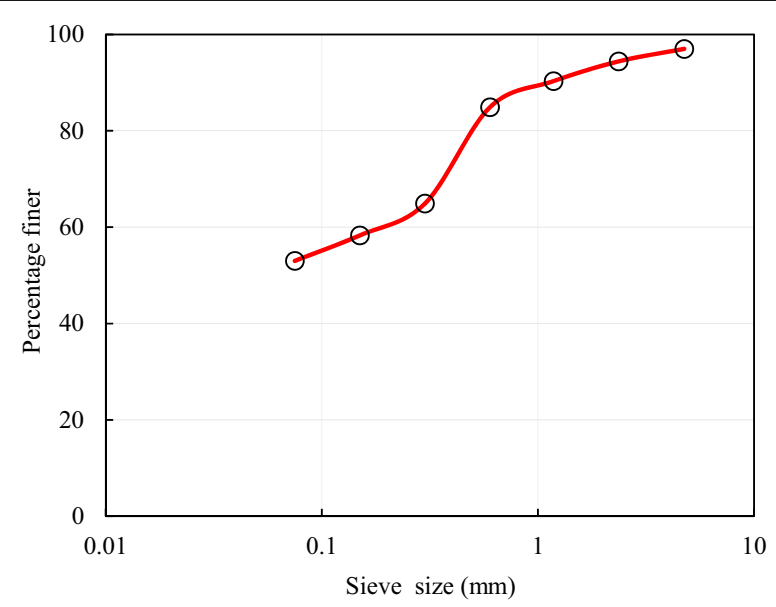

Fig. 1 Grain size distribution curve of clayey subgrade 
were conducted as per IS: 2720 (Part 5)-1985 [13]. Grain size distribution is as per IS: 2720 (Part 4)-1985 [14]. Standard proctor compaction test was carried out according to IS: 2720 (Part 8)-1983 [15]. The California Bearing Ratio (CBR) test was carried out as per the IS: 2720 (Part 16)-1987 [16]. The UCS test was carried out as per the IS: 2720 (Part 10)-1973 [17]. The specific gravity of soil was carried out as per the IS: 2720 (Part 3/Set I)-1980 [18]. Determination of Free Swell Index (FSI) of soil was carried out as per the IS: 2720 (Part 40)-1977 [19].

\section{Discussion of results}

\section{Liquid limit and plastic limit}

Liquid limit and plastic limits are well known as Atterberg limits and are very useful to assess the consistency of fine-grained soils. In general, clay poses a lot of construction problems in the presence of moisture content. If the natural moisture content (NMC) of clay is very close to its LL, the soil will behave like a soft consistency and can be prone to excessive settlement and finally leads to strength reduction.

The variation of Atterberg limits with RBI Grade 81 is presented in Fig. 1. From this figure, it can be seen that as the percentage of RBI Grade 81 increases from 0 to $8 \%$, LL is decreasing linearly, whereas the PL is seen increasing almost linearly and the LL and PL both are meeting at a point corresponding to $8 \%$ of RBI Grade 81 . PI (it is the numerical difference between LL and PL) is gradually decreasing and showing almost a non-plastic range values. At $8 \%$ RBI Grade 81 , the PI is almost less than 1 . Hence the addition of RBI Grade 81 to clay soil a drastic decrement in PI and consequently turning the soil behaviour into non-plastic (Fig. 3).

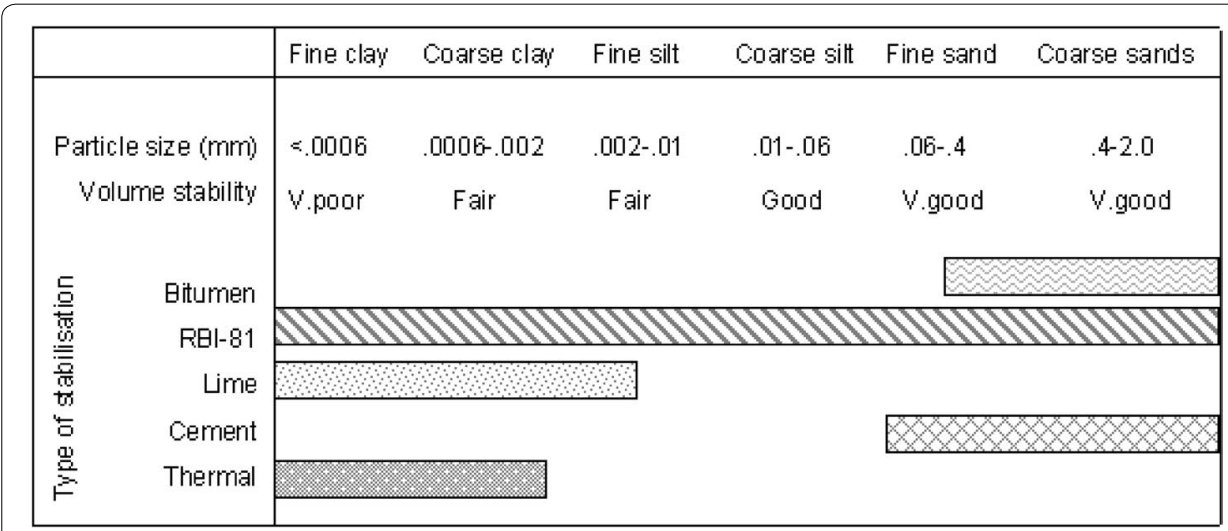

Fig. 2 Spectrum range of RBI Grade 81

Table 2 Physical properties of RBI Grade 81

\begin{tabular}{ll}
\hline Physical properties & Average value \\
\hline Odor/color & 4.2 \\
Loss on ignition & 2.5 \\
Specific gravity & 2.5 \\
\% passing through $75 \mu$ & 98 \\
Polyester fiber (\%) & 0.23 \\
\hline
\end{tabular}




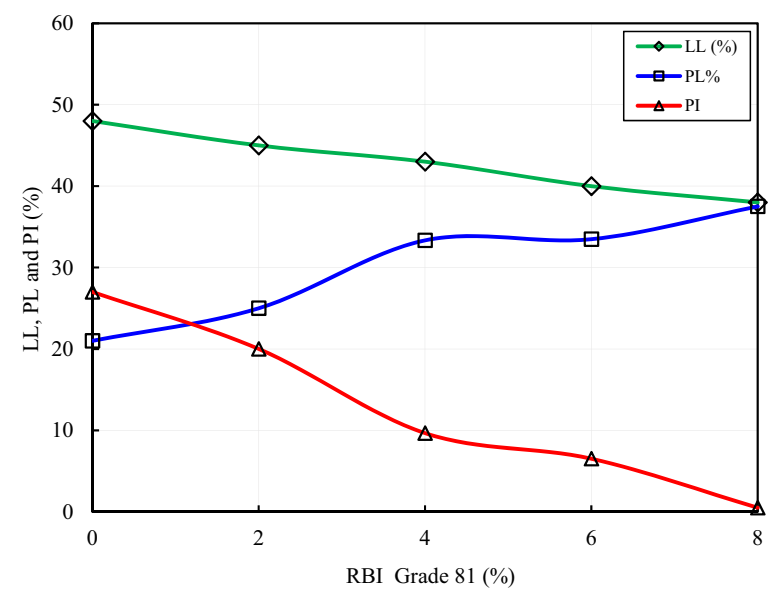

Fig. 3 Variation of LL, PL and PI with RBI Grade 81

\section{Compaction characteristics}

Compaction is a mechanical process in which can be carried out mainly to improve the soil density, strength and to reduce the unwanted settlements of the subgrade. In highway projects, compaction characteristics of the subgrade such as optimum moisture content (OMC) and maximum dry density (MDD) are the key parameters, especially in quality control process. So these values can be considered as key quantities for laying the pavement subgrade and must be maintained to attain the stable structure. The compaction curves for the addition of different percentages of RBI Grade 81 mixtures are presented in Fig. 4.

The compaction curves show that as the percentage of RBI Grade 81 increases from 0 to $8 \%$, the peaks are shifting forward right. Almost all the curves are following the similar trend with the addition of the additive. From these curves, it can be further noticed that as the increase in the percentage of RBI Grade 81, the MDD of soil decreasing with the increment of moisture content. This decrease in MDD can be attributed to the replacement of soil with lightweight admixtures such as RBI Grade 81 . This replacement of soil by RBI Grade 81 imparts strength to the soil mixtures due to the formation of cementitious compounds; in turn, it develops a good bonding and hence there is an improved stability to the subgrade (Table 3).

Mechanisms governing the compaction characteristics can be better understood from the results as presented in Fig. 5. It can be seen from the above figure that, a decrease in MDD due to the flocculation as a result of physicochemical interaction between the particles and its groups. It is known that flocculated structure as a result of the formation of cementitious bonding makes the compaction more difficult owing to the greater shear resistance at particulate level. Also, the RBI Grade 81 simply replaces the clay particles and the behavioural pattern is nearly governed by itself. The OMC values are also increasing with the RBI Grade 81 . This is due to the addition of RBI Grade 81 causing the formation of the matrix; owing to the greater placement of water content is required to obtain the MDD. 


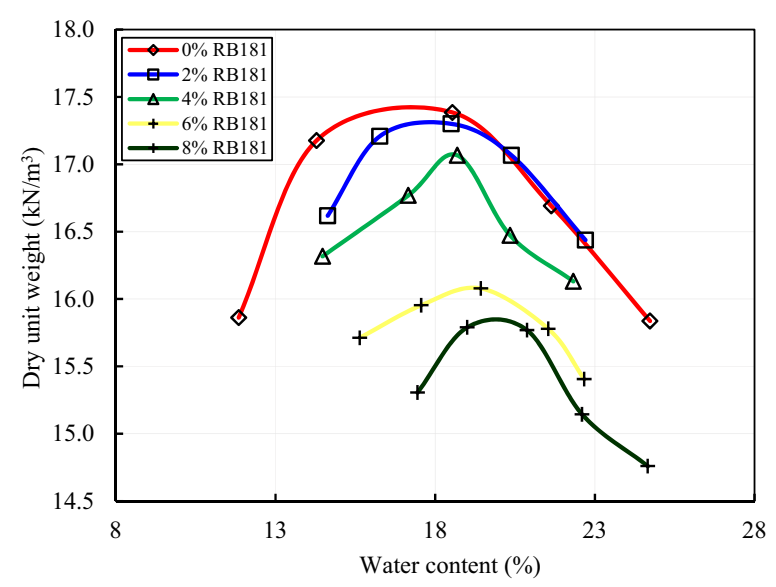

Fig. 4 Compaction curves for admixed soil mixtures

Table 3 Chemical properties of RBI Grade 81

\begin{tabular}{ll}
\hline Chemical properties & Average value (mg/l) \\
\hline $\mathrm{NaHCO}_{3}$ & 96 \\
$\mathrm{CaSO}_{4} \cdot 2 \mathrm{H}_{2} \mathrm{O}$ & 60 \\
$\mathrm{MgSO}_{4}$ & 60 \\
$\mathrm{kCl}$ & 4 \\
$\mathrm{pH}$ & 8 \\
\hline
\end{tabular}

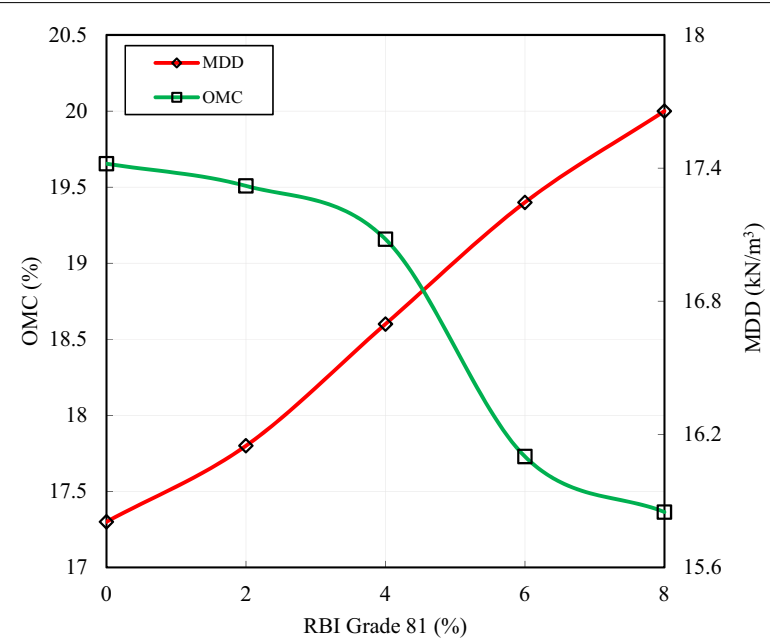

Fig. 5 Variation of OMC and MDD with RBI Grade 81

\section{Effect of RBI Grade 81 on UCS}

The stress-strain curves for various percentages of RBI Grade 81 mixtures are presented in Fig. 6. From these curves, it is observed that the curves are following a similar trend, but the failure strain is decreasing as the addition of RBI Grade 81 . About $1-2 \%$ of strain, the curves are following the linear trend and thereafter the curves changed to curvilinear 


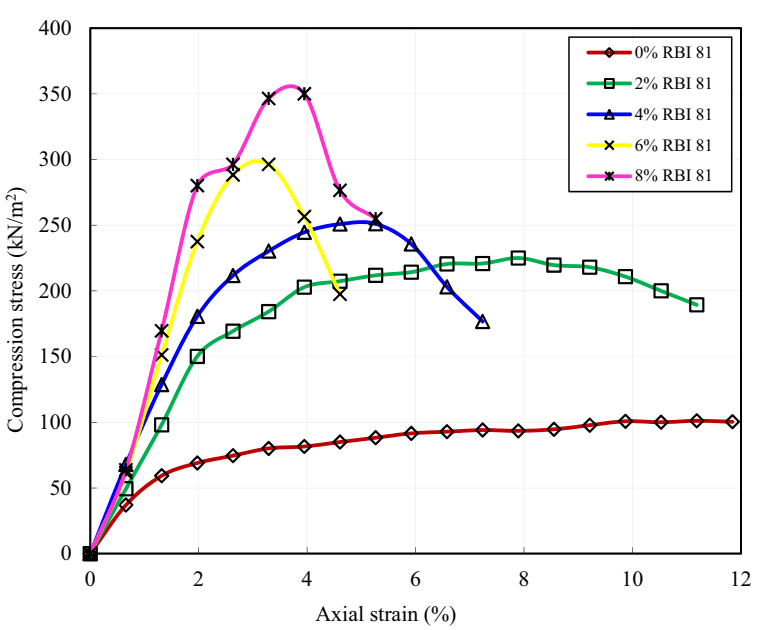

Fig. 6 Stress-strain curves of admixed soils

trend. Further, increase in dosage of RBI Grade 81 causing the soil to fail by brittle nature instead of plastic failure.

The above figure might be helpful to the designers in selecting the respective value of unconfined compression stress (UCS) and strain for a given dosage of RBI Grade 81. The variation of UCS with RBI Grade 81 is presented in Fig. 7. From this figure, it can be seen that the UCS is increasing linearly with the increase in RBI Grade 81 . This increment in UCS at $8 \%$ RBI Grade 81 is 3.5 times as compared to the untreated soil. It can be observed that addition of RBI Grade 81 imparting an improvement in the soil subgrade strength. Also, the similar improvement is noticed for the cohesion of soil.

\section{Effect of RBI Grade 81 on CBR}

The CBR of highway stratigraphy plays a vital role in the design of flexible pavement [20]. The load-penetration curves of CBR tests for the various dosage of RBI Grade 81 are presented in Fig. 8. From this figure, it is noticed that all the curves are following a

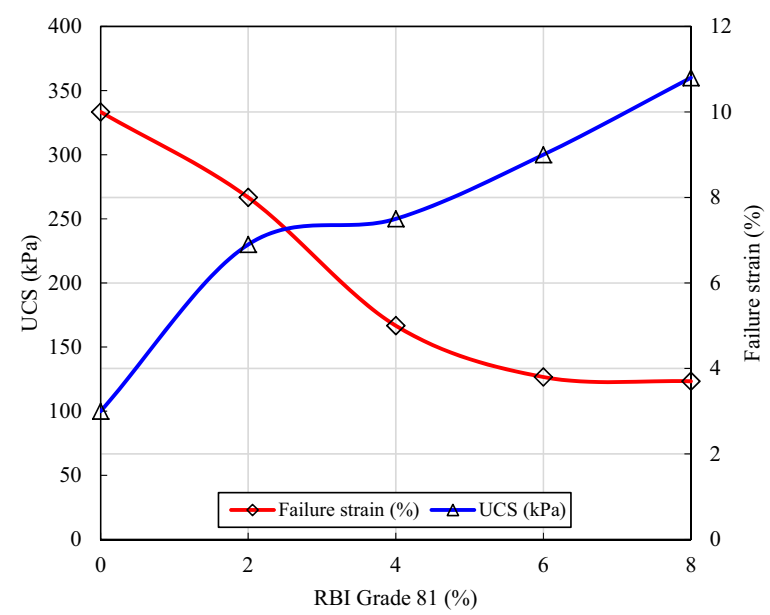

Fig. 7 Variation of failure strain and UCS of admixed soil 


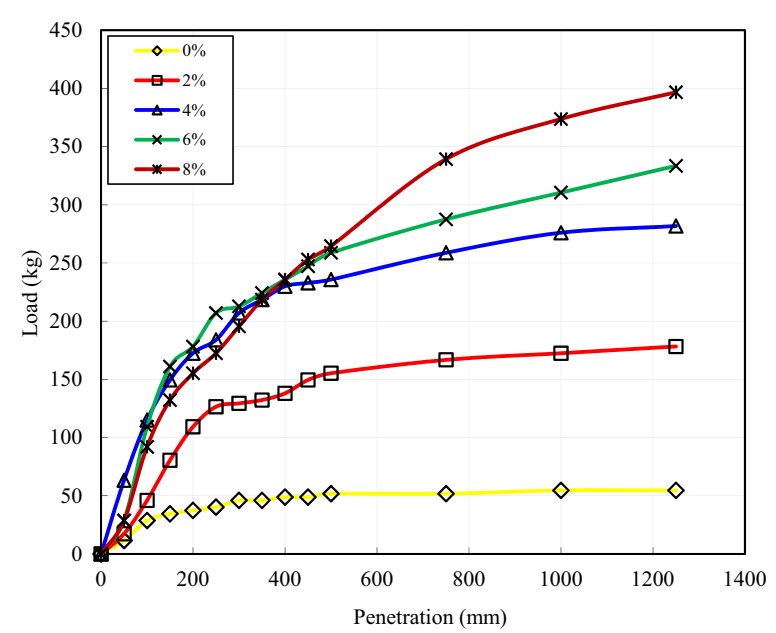

Fig. 8 Load-penetration curves of admixed soil

comparable trend. The load per unit penetration is increasing gradually as RBI Grade 81 increases from 0 to $8 \%$. In addition, further addition of RBI Grade 81 developing rigid matrix in the presence of moisture equivalent to OMC and hence taking more load for a specified penetration in the CBR mould.

\section{Relating curves between CBR and soil basic properties}

To read or select the other properties along with the CBR such as MDD, OMC, UCS and cohesion for a various percentage of RBI Grade 81 mixed with soil subgrade are presented in Figs. 9, 10, 11 and 12. From these figures, for a given dosage of RBI Grade 81, it is possible to read or select the required information such as OMC, MDD, UCS, and Cohesion of clay soil. For instance, corresponding to 6\% RBI Grade 81, the soil properties noticed are CBR is $14 \%$, UCS is $300 \mathrm{kPa}$, cohesion is $150 \mathrm{kPa}, \mathrm{OMC}$ is $19 \%$ and MDD as $15.85 \mathrm{kN} / \mathrm{m}^{3}$.

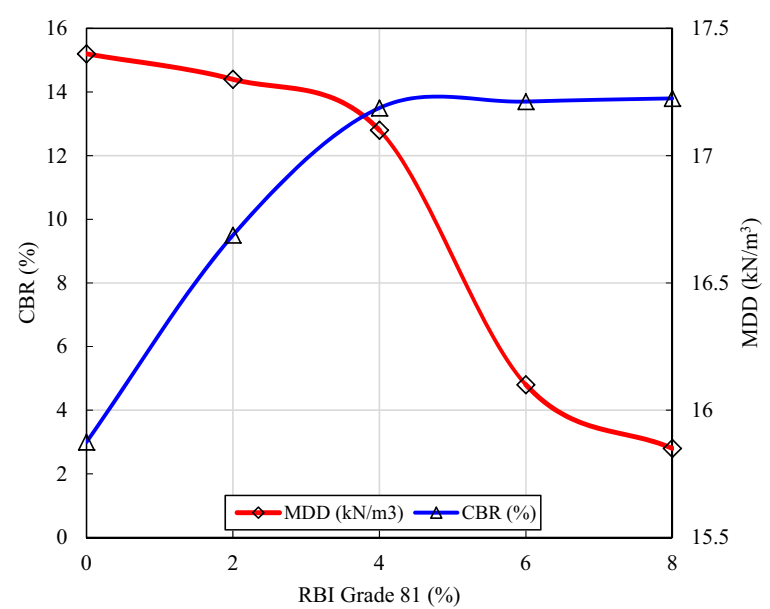

Fig. 9 Variation of CBR and MDD with RBI Grade 81 


\section{Conclusions}

A stable and durable pavement is the one which provides a safe, comfortable and economical movement of the traffic flow. If the existing ground has no adequate strength, either replacing the soil from other sites or the existing soil stabilized with various techniques to attain the required strength to bear the wheel/traffic loads. In view of the expected improvements in the soil subgrade, the locally available clay soil stabilized with RBI Grade 81 significantly improved the geotechnical properties of the subgrade. From the above results and discussions, the following key conclusions are drawn.

Atterberg limits such as LL, PL, and PI have shown marked changes in soil treated with RBI Grade 81. LL has decreased linearly, whereas PI increased almost linearly and LL and PL both are reached the same point at $8 \%$ of RBI Grade 81 .

The OMC has increased with the increase in dosage of RBI Grade 81, whereas the MDD is decreased. The UCS has increased linearly with RBI Grade 81 and at $8 \%$ of

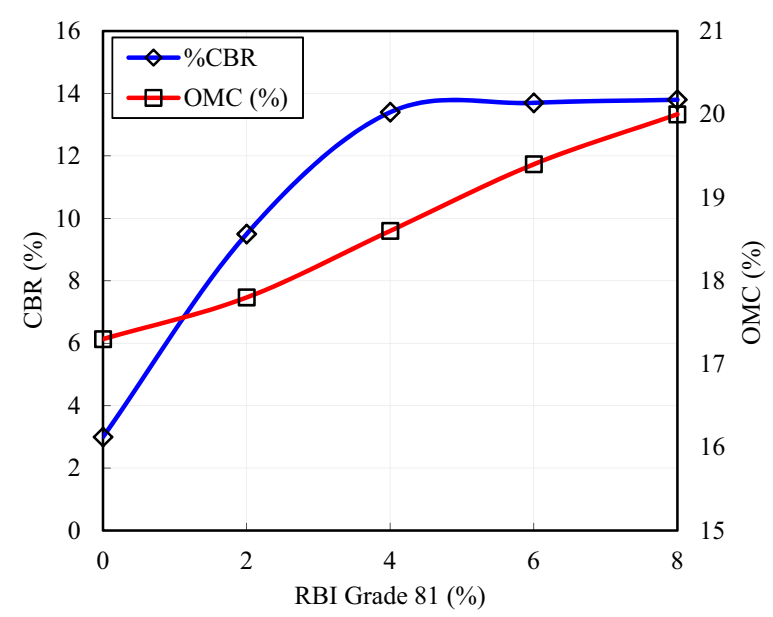

Fig. 10 Variation of CBR and OMC with RBI Grade 81

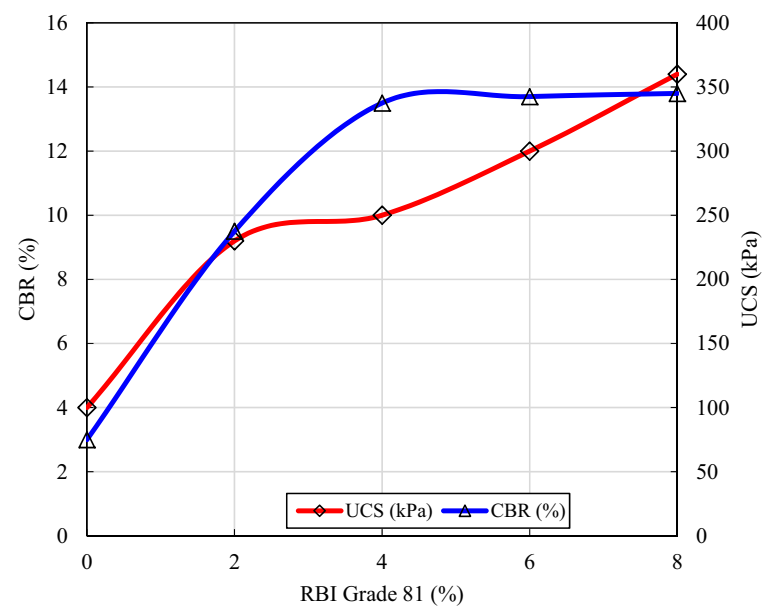

Fig. 11 Variation of CBR and UCS with RBI Grade 81 


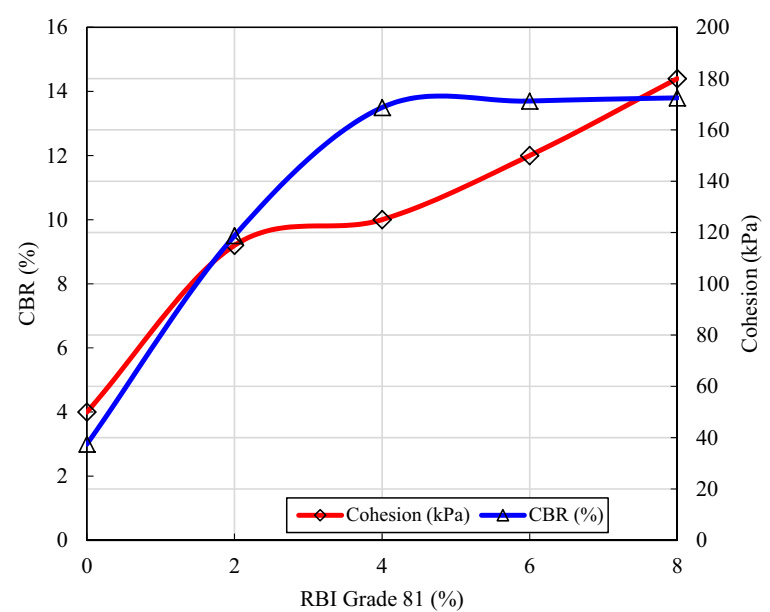

Fig. 12 Variation of CBR and cohesion with RBI Grade 81

RBI Grade 81, it is 3.5 times higher as compared to the untreated soil. Also, the failure strain in the stress-strain curves became lower with the increased dosage of RBI Grade 81.

CBR of clay soil has increased with RBI Grade 81 and this improvement is observed up to $4 \%$ of RBI Grade 81 and thereafter no marked improvement is noticed.

Authors' contributions

Both authors involved in compiling the whole manuscript write-up and finally read and approved for the submission. Both authors read and approved the final manuscript.

\section{Author details}

${ }^{1}$ Department of Civil Engineering, Xi'an Jiaotong-Liverpool University (XJTLU), Suzhou, Jiangsu province, China. ${ }^{2}$ Department of Civil Engineering, JNT University Hyderabad, Hyderabad, Telangana, India.

\section{Acknowledgements}

The authors are grateful to Mr. Nagabushanam and Mr. Mallesh for their kind cooperation in the laboratory during experimentation.

\section{Competing interests}

The authors declare that they have no competing interests.

\section{Ethics approval and consent to participate}

Not applicable.

\section{Publisher's Note}

Springer Nature remains neutral with regard to jurisdictional claims in published maps and institutional affiliations.

Received: 12 July 2017 Accepted: 16 November 2017

Published online: 24 November 2017

\section{References}

1. Kumar KSP, Kumar MA, Kumar ND (2017) Prophecy of plate load test response from theory of elasticity solution and CBR test. Jordan J Civ Eng 11(3):335-345

2. Madurwar KV, Dahale PP, Burile AN (2013) Comparative study of black cotton soil stabilization with RBI Grade 81 and sodium silicate. Int J Innov Res Sci Eng Technol 2(2):493-499

3. Jayatheja M, Kumar ND, Kumar SPK (2016) Influence of zycosoil on consolidation, shear strength characteristics and permeability of clayey subgrade. In: 10th international conference on lowland technology, Manglore

4. Venugopal G, Chetan Fakkerappa B (2014) Studies on black cotton soil stabilization using RBI Grade-81. Int J Innov Res Sci Eng Technol 3(12):18205-18210

5. IRC-37-2012-Guidelines-for-the-design-of-flexible-pavements-third-revision 
6. Lekha BM, Shankar AUR (2014) Laboratory performance of RBI 81 stabilized soil for pavements. Int J Civ Eng Res 5(2):105-110

7. Mamta A, Mallikarjun H (2014) Using RBI Grade 81: a comparative study of black cotton soil and lateritic soil. Int J Res Eng Technol 3(3):613-616

8. Haricharan TS, Kumar VKS, Prashanth LD, Archana MR, Ravishankar AU (2013) Laboratory investigations of expansive soil stabilized with natural inorganic stabilizer. IC-RICE Conference Issue 2013, pp 201-204

9. Ratna Prasad R, Darga Kumar N, Janardhana M (2013) Effect of fly ash on CBR and DCPT results of granular sub base subjected to heavy compaction. Int J Sci Eng Res 4(5):51-56

10. Ramadas TL, Kumar ND, Yesuratnam G (2012) A study on strength and swelling characteristics of three expansive soils treated with $\mathrm{CaCl}_{2}$. Int J Adv Civ Eng Arch 1(1):77-86

11. Anitha KR, Ashalatha R, Johnson AS (2009) Effects of RBI Grade 81 on different types of subgrade soil. In: 10th national conference on technological trends (NCTT09). pp 6-7

12. Sushanta B (2010) Stabilization of blast furnace slag and fly ash using lime and RBI Grade 81. B.Sc thesis, Department of Civil Engineering, NIT, Rourkela

13. IS: 2720 (Part 3/Set I)-1980. Methods of test for soils: Part 3 determination of specific gravity, Section I fine-grained soils

14. IS: 2720 (Part 4)-1985. Methods of test for soils: Part 4 grain size analysis

15. IS: 2720 (Part 5)-1985. Methods of test for soils: Part 5 determination of liquid and plastic limit

16. IS: 2720 (Part 7)-1980. Methods of test for soils: Part 7 determination of water content-dry density relation using light compaction

17. IS: 2720 (Part 10)-1973. Methods of test for soils: Part 10 determination of unconfined compressive strength

18. IS: 2720 (Part 16)-1979. Methods of test for soils: Part 16 laboratory determination of CBR

19. IS: 2720 (Part 40)-1977. Methods of test for soils: Part 40 determination of free swell' index of soils

20. Kumar KSP, Kumar ND (2016) Use of CPT and DCP based correlations in characterization of subgrade of a highway in southern Ethiopia Region. Int J GeoEng 7(1):15. https://doi.org/10.1186/s40703-016-0025-8

\section{Submit your manuscript to a SpringerOpen ${ }^{\odot}$ journal and benefit from:}

- Convenient online submission

- Rigorous peer review

- Open access: articles freely available online

- High visibility within the field

- Retaining the copyright to your article

Submit your next manuscript at $\mathbf{s p r i n g e r o p e n . c o m ~}$ 